\title{
Software Engineering
}

2020; 8(3): 13-23

$\mathrm{http}: / /$ www.sciencepublishinggroup.com $/ \mathrm{j} / \mathrm{se}$

doi: $10.11648 /$ j.se.20200803.11

ISSN: 2376-8029 (Print); ISSN: 2376-8037 (Online)

\section{Creative Communication Safe Ethical Artificial Intelligence in the Era of Technological Development}

\author{
Evgeny Bryndin \\ Research Center «Natural Informatics», Novosibirsk, Russia
}

\section{Email address:}

bryndin15@yandex.ru

\section{To cite this article:}

Evgeny Bryndin. Creative Communication Safe Ethical Artificial Intelligence in the Era of Technological Development. Software Engineering. Vol. 8, No. 3, 2020, pp. 13-23. doi: 10.11648/j.se.20200803.11

Received: December 6, 2020; Accepted: December 15, 2020; Published: December 28, 2020

\begin{abstract}
God created the universe by images. Man also carries out creative activity by imagined and descriptive images. Creative artificial intelligence can already create paintings, compose poems and prose. That is, he can imagine and depict virtual animated and inanimate images. Creative artificial intelligence can also endow virtual images with information and process active communications that are safe for their environment. That is, make them active. Intelligent communicativeassociative artificial intelligence combines information and active communications. Digital doubles and robots with artificial intelligence can embody virtual images with information, process active and safe communications in real participants in the social life of a technocratic civilization by self-organizing ensembles of intellectual agents with collective synergistic interaction. An ensemble of intelligent virtual agents can simultaneously interact with several external environments, conduct several dialogues and perform many skills, that is, can have collective knowledge and skill and behavior. The author, in this article, proposes a synergistic approach to the formation of technological ensembles of intelligent virtual agents. The synergistic approach created reference positions for the development of a new promising area of informatics. A synergistic approach establishes the relationships and from the image of conjugated system phenomena. It uses tools, approaches, and methodology to reasonably transfer the results of subsystem research, parts, and sections to their integral integrated and hierarchically superior system levels. The synergy approach shows the most important role of resonant phenomena of the states of information systems. The synergistic principle provides a single basis for self-organization. The stage of self-organization occurs only in the case of positive feedback. A synergistic approach allows you to implement the self-organization of intelligent virtual agents of the technological ensemble. Technological self-organizing collective ensembles are able to interact with production teams, replace them for some time and even completely release them in various fields of professional activity. Technological collective ensembles can manage industries, make decisions in difficult changing circumstances and ensure safety in extreme conditions.
\end{abstract}

Keywords: Information and Process Communications, Intelligent Agents, Collective Synergy, Digital Doubles, Robots

\section{Introduction}

Artificial intelligence was capable of creativity. Lifesaving strong artificial intelligence is capable of learning, retraining, self-realization and development by improving functional activities by mastering creative innovative hightech professional and behavioural skills and competences according to criteria of preferences with qualitative choices.

Neural networks have learned to paint paintings, compose music and poems, and invent scripts for films. Yandex teaches neural networks to record music albums similar to those of popular bands and write poems. The principle of operation of all algorithms is similar: they analyze a huge array of works of art, and then on the basis of the obtained patterns create their creation: The PIX18 algorithm invented by Creative Machines Lab can generate works based on photos at its disposal. Paintings created by Google's DeepDream algorithm are considered practically art. Neural networks can even create a new one. Developers from the Laboratory of Artificial Intelligence and Art of Ratger University, created a generative-adversarial network GAN of two discriminators. An algorithm based on the answers of one discriminator analyzed the paintings, drew its own and checked the result. He produced images similar to those he 
had studied before. The second discriminator, analyzes about 81 thousand paintings and, based on such a voluminous sample, forms a list of conditions under which the created painting can be classified as works of art. At the same time, the second discriminator makes a list of styles and checks the picture for similarity with them - carries out a verification operation. A new painting is born when the image is recognized as a work of art not identical to any of the preexisting styles. The GAN network follows creativity, produces new paintings that provoke emotional response in people.

Project Alejandro Giacometti of EDITED, an analytics company for the retail. During the experiment, he recognized thousands of images from the podiums of the spring show of London Fashion Week in 2017, which allowed allocate to the photo the image of individual parts of clothing. For this purpose, a system of two neural networks was used: the first subnet formed a unique representation of the input image in the form of a set of real numbers, and the second restored the original image from it. In the course of training, the parameters of these subnets were selected so that obtained picture was as similar as possible to the original. Thus, the first subnet was able to learn to obtain compact information from the visual image of clothing, which became possible to analyze - for example, to assess the similarity of two outfits among themselves. The second subnet made it possible to create a "digital model" of outfits, describing dozens of parameters of each. When researchers accumulated enough data, they were able to teach the computer to distinguish the models of one designer from others, to find characteristic elements of style. Moreover, it became possible to predict the emergence of new collections, to predict consumer demand.

Google, along with the German company Zalando SE, have created a neural network that helps designers determine which styles and clothes will suit certain people and be in demand. For consumers, the technology helps to select clothes based on responses to the questionnaire and test drawing.

The service "Ivanex Autopate," which was created in December 2013, has been making poem lines based on requests of users and news headlines for several years. For this purpose, the robot was specially taught to determine poem dimensions and rhyme lines among themselves.

Employees of the Moscow Automobile and Road Technical University have developed artificial intelligence, which has multifunctional abilities: manages different modes of ground transport, aircraft, solves complex geometric tasks, know how to build long logical chains.

In the international professional community, creative lifesaving strong artificial intelligence becomes almost relevant [1].

\section{Communicative Associative Smart Artificial Intelligence Technology}

Let $\mathrm{S}$ be a spelling dictionary, where $\mathrm{S}=\{\mathrm{Si}\}, \mathrm{Si}$ is a morphological word. The word Si refers to the Qij feature of the Mij representative from the Mi set, where $\mathrm{Mi}=\{\mathrm{Mij}\}$.
Denote the lexical meaning of the word Si via $\{\mathrm{Mij}, \mathrm{Qij}, \mathrm{Si}\}$. The relationship of the lexical values of words $\{\mathrm{Si}\}$ with elements of the set $\mathrm{Mi}$ is given by the set of feature relations Qi, where Qi $=\{$ Qij, (Mi, Mij) $\}$.

A set of lexical values associated with a set of characteristic relations with representatives is an essential dictionary. Words in the dictionary are supplied with characteristic indexes according to their characteristic relationships with representatives. The entity dictionary captures the characteristic entities of representatives. The dictionary helps to use words with its lexical meaning and distinguish between representatives whom they call on a symbolic level.

Words are used based on characteristic indices. Each feature has three indexes. One index indicates the subject area of knowledge, the second indicates the situation, the third indicates the situational moment. Words with multiple lexical meanings have multiple sets of indexes. For example, flour and flour. The word field is used in various subject areas. Each set of indexes defines a lexical word value.

Tasks, problems, tasks and goals are formed in the form of information needs. The text of the information requirement is based on the functional natural language from the elements of the essential dictionary. Functional natural language describes communicative and associative relationships between knowledge elements. Communicative and associative language relationships between knowledge elements follow the relationships of objects, actions, qualities, properties, time, space, etc., which we denote knowledge elements.

The language links the structural, functional and semantic attributes of knowledge elements. The use of words as part of information demand knowledge elements is defined by communicative links. The language has grammatical rules for the speciation of word forms for the creation and expansion of families and the creation of communities, communicative rules for the formation of phrases, sentences of judgments. Each rule has its own definition area. For example, in a deductive generalization rule, the domain of the definition is deductive sets. Deductive rules allow you to organize language words into generalized sets. The generalized set is represented by a convergent feature. The private values of the convergent characteristic are its specificity. In the language, the emphasis in the word, in the sentence, in the judgment between sentences is fixed by synthactics. If the shock words in the sentences are highlighted in bold, then their semantic development follows. Communicative relationships of content sentences have syntactic notations.

According to the act, ascending parsing and morphological analysis identifies sentences of information need that correspond to acts of thinking and establishes grammatical types and characteristics for each word according to a dictionary of semantic orientation, builds a tree of syntactic subordination of words, determines the communicative relationship of words, phrases and sentences. For analysis, you use an essential dictionary, networks of phrases, sentences, judgments, information families, and communities.

Parsing is carried out by language syntax markup of 
information demand and its structural situationalcharacteristic markup. By parsing, the grammatical values of knowledge elements are determined, words in sentences, phrases in sentences, sentences in judgments, elementary judgments in composite judgments are distinguished, grammatical types of words, species groups of phrases according to grammatical types of words of basics and additional, grammatical types of lexical values of information niches of sentences, and species relationships of sentences of elementary judgments are identified.

Morphological analysis is carried out according to linguistic morphological markup and schematic situational-characteristic. In the process of morphological analysis, morphological values of knowledge elements and situational-characteristic schemes of morphological values are determined.

The selection of sentences is carried out according to a syntactic structure, in which words are assigned features and indexes of representatives, grammatical types and lexical values, semantic values to phrases. The information niches of the quotation are determined by the act-based upstream parsing and morphological analysis of the information demand texts. The resulting text, after an act analysis, enters the system of symbolic and linguistic implementation of information needs - a system of imitation of thinking.

The input information of the system is the information demand and attributes obtained in the process of syntactic and morphological analysis. According to information obtained as a result of syntactic and morphological analysis of information demand, the system of imitation of thinking carries out its semantic analysis.

The information requirement type is first recognized. The information need may be questionable or prompting. Semantic analysis then determines whether there is an implementation of the knowledge base information requirement. If it is not implemented, it is determined whether the information requirement is a typical baseline. If the information requirement is not a generic basic requirement, the analysis determines whether it consists of a generic basic information requirement. If it does not consist of generic basic information needs, semantic analysis determines whether there is a necessary and sufficient set of implementation procedures in the knowledge base and a necessary and sufficient set of knowledge elements in the knowledge base to implement it.

If, as a result of analysis, it turns out that in the knowledge base there are elements for realizing the information need, then the simulation system of thinking forms the implementation of the information need from the knowledge elements of the information need and the knowledge elements for implementation from the knowledge base. By marking the text of the information demand, the system determines pointers to the necessary sets of knowledge elements in the knowledge base in the subject area specified by the user, and to the implementation procedures in the skill base, and determines the implementation scheme according to the type and layout of the need.

The markup indicates the attributes of knowledge elements: schematic, characteristic, grammatical (syntactic, morphological), semantic and lexical.

Pointers to knowledge and implementation elements are formed through an information receptive field. The information receptive field contains information connections with inputs of a network of phrases, sentences, judgments, as well as with implementations of typical basic information needs. It contains instructions on the necessary and sufficient set of implementation procedures for each lexical value of the information action and on the necessary and sufficient set of knowledge elements for each implementation procedure, as well as information links with implementation procedures stored in the skills base.

Markup of information demand and user-defined area of knowledge is used to define pointers to find necessary and sufficient set of implementation elements in the knowledge base, necessary and sufficient set of knowledge elements in the knowledge base, schemes and structures of formation of new phrases, sentences, judgments.

The system of simulation of thinking starts the procedure of building a network of element-by-element realization of information demand from the necessary and sufficient set of knowledge elements and implementation procedures. It builds a network of element-by-element implementation of information needs in databases of knowledge and skills. It then performs initial markup of knowledge elements and implementation procedures and their relationships. Markup defines the characteristic participation of words in phrases, the situational-characteristic participation of phrases in sentences and the situational participation of sentences in judgments.

After marking the element-by-element implementation network, it is launched to realize the information demand. Information needs are considered feasible if the syntax structure of the implementation, lexical and semantic values of the components, as well as implementation procedures are determined. If the input information requirement is a combination of typical information requirements or a valid modification thereof, it is realizable. A typical incentive information requirement consists of an information action and an information condition. If the information need is prompted, then it explicitly indicates the action. If the information requirement or the information requirement realization contains an information action, then the standard realization procedure is started. Reference to implementation procedure is indicated in information action markup. After implementation, the new information need is entered into the knowledge base and linked to the knowledge element, which is its implementation.

The technology of implementing the communicativeassociative logic of imitation thinking allows you to develop interactive educational systems of a natural language level in various subjects in the educational space. The subject area of knowledge is presented in the form of a communicativeassociative network of information needs and their implementations, consisting of elements of knowledge. Communicative phrases form sentences, communicative sentences form judgments. The association between the information need and its implementation is associative. 
The words of information demand have markup indicating either a lexical value, or a computational procedure, or a behavioral procedure. For example, the word "add" can be a lexical value, either an arithmetic action or a behavioral action (add cubes). For judgments, the subject area and situation are indicated. For quotations, you specify the situational moment and the characteristics of the lexical values. The reflection of the semantics of subject knowledge is carried out using a symbolic-linguistic sign system based on communicative-associative logic and subject-situationalcharacteristic relations of entities of reality and abstraction objects with knowledge elements of the essential dictionary.

The information demand implementation system uses a knowledge base and a skill base. The implementation of the information demand is taken either from the knowledge base, or is developed by a typical procedure for implementing the skills base according to the current information demand, or a network of element-by-element implementation according to the combined information demand is formed. Schemes for implementing information needs are obtained from a study of educational practices in the formation of imitative thinking. The diagrams are shown in Figures 1-2.

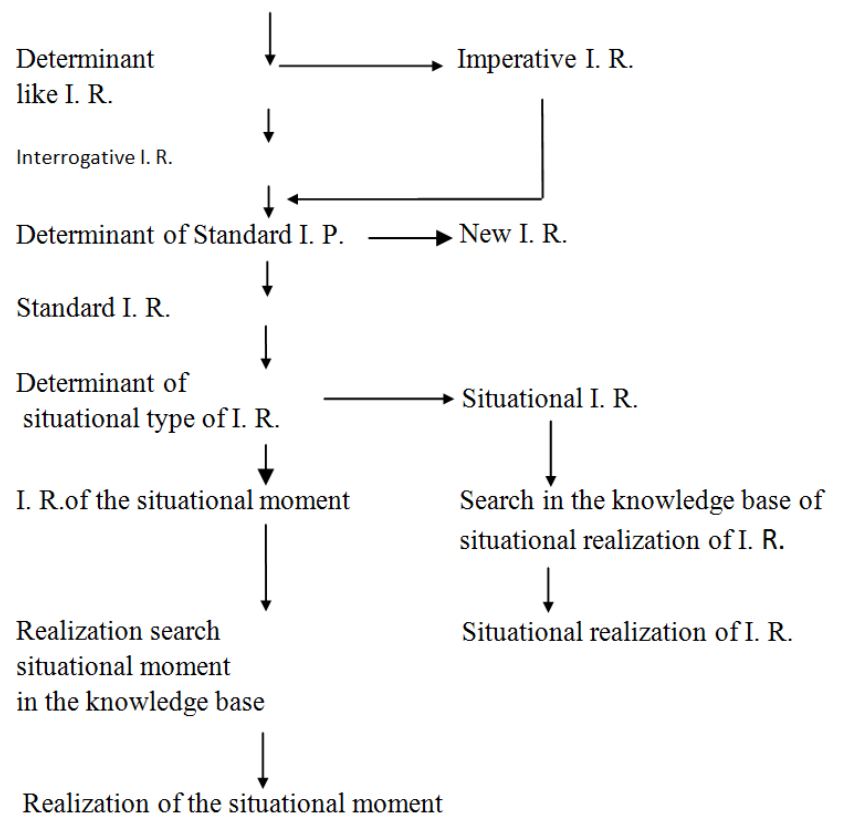

Figure 1. Realization of standard information requirement (I. R.).

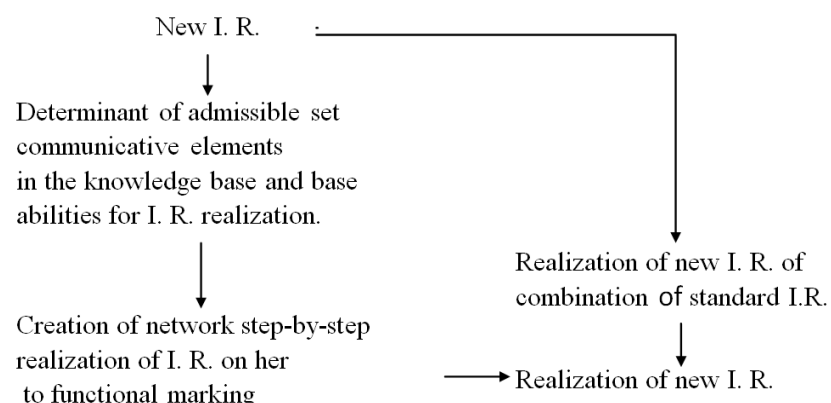

Figure 2. Realization of new information requirement (I. R.)

After implementation, the new information need is entered into the knowledge base and associated with the knowledge element, which is its implementation. The variation of such information needs is carried out in a variable part, which are implemented by standard procedures common to them.

The realization of combined information needs is developed by the investment, variation and combination of implementations of information needs, which are located in the knowledge base of the system. New information needs are built either by sequentially merging existing needs from implementations, by investing one in another, or by merging and investing at the same time.

Intelligent communicative associative artificial intelligence will coordinate language and active communications [2].

\subsection{Communicative-associative Development of Smart Artificial Intelligence}

At the present stage of the development of information technologies, cognitive robotization, digital doubles and artificial intelligence systems, their synergy allows us to begin to form rational intelligent artificial intelligence in virtual space. The author proposes to develop cognitive virtual intelligent artificial intelligence by ensembles of diversifying agents with strong artificial intelligence based on communicative-associative logic by recurring development of professional skills, increasing visual, sound, subject, spatial and temporal sensitivity. To do this, several diversifying agents who try to get the same conclusion will give a more accurate result, so several diversifying agents are combined into an ensemble. Then, based on the criteria of utility and preference, the final result is obtained based on the conclusions of diversifying agents. This approach increases accuracy. Bagging and Boosting techniques are used to form ensembles. Bagging is a combination of independent diversifiable agents by averaging patterns (weighted average, majority vote, or normal average). Boosting is the construction of ensembles of diversifiable agents consistently. The idea here is that the next agent will consider the errors of the previous agent. Due to the fact that diversifiable agents take into account errors committed by previous agents, it takes less time to get to a real response. The combination of Bagging and Boosting decision-making methods allows the development of intelligent artificial intelligence by ensembles of diversified agents. Cognitive virtual intelligent artificial intelligence becomes smarter through the accumulated professional experience of high-tech skills, competencies and knowledge, having increased visual, sound, subject, spatial and temporal sensitivity. Many researchers believe that the information technology industry is on the verge of a transition to smart universal artificial intelligence. The information technology industry is trying to find the boundaries of smart artificial intelligence. The use of ensembles of intelligent compatible diversified agents will help to find boundaries in which smart artificial intelligence will benefit humanity and not harm. For this purpose, according to the ethical standard, they are endowed with useful information and active communications [3] 


\subsection{Self-organizing Ensembles of Intelligent Agents with Synergistic Interaction}

Technological collective ensembles use intellectual agents for the solution of one general difficult complex task. Agents make the action plans, being based already not only on the opportunities, but also on the basis of plans and intentions of other agents. For this purpose the ensemble needs to carry out a set of tasks:

1. formation of the joint action plans;

2. accounting of interests of partners of agents;

3. organization of negotiations on joint actions;

4. synchronization of joint actions;

5. recognition of need of cooperation;

6 . choice of the suitable partner;

7. training in rules of conduct in collective;

8. decomposition of tasks and segregation of duties;

9. joint obligations, etc.

To organize an ensemble of agents with artificial intelligence in the likeness of human society, they are associated with systemic analysis, the theory of organizations, and the theory of management. An unresolved problem is the moral ethical basis of the organization, associated with the formation of concepts about the basic values and norms adopted in society. It is proposed to focus on models of regulatory behavior of agents. Problems of collective normative behavior are considered in system theory, in control theory and in game theory. The main idea of system analysis is to apply the decomposition of the original problem into simpler ones, from the solution of which a solution to the problem as whole can be found.

In ensembles, it is proposed to use the synergistic principle of interaction of agents with artificial intelligence for distributed re-creation of subtasks, as a strategy of number of collective behavior. The ensemble of agents with artificial intelligence is built as a self-organizing non-equilibrium thermodynamic system, which makes it possible to navigate in a difficult environment, deal with fuzzy tasks, adapt to changing conditions. They are able to solve complex problems on their own in conditions of uncertainty and high dynamics of change.

The main law of the ensemble organization is the law of synergy: the sum of the properties of the organized whole exceeds the sum of the properties available to each of the elements included in the whole separately. The most important feature of the system is the presence of qualities that are not reduced to the sum of the qualities of its constituent elements.

An important indicator of the sustainability of the organization as a holistic system is the nature of interaction with the environment. The self-regulation of the system consists in the fact that with internal or external influence on the system, some of its elements acquire dysfunctional properties, and in order to preserve themselves, the system seeks to neutralize these dysfunctions. The highest stage in the development of forms of regulation is management. The systems have a number of regulators subordinate to each other. Regulation as a process is a change in the relationship of elements of the system aimed at preserving it, and control is a process of transmitting information over communication channels, in which the functional nature of the properties of these elements is maintained and enhanced.

In the course of its existence, any organization undergoes certain changes, characterized by a change in its internal properties and characteristics, improvement in functioning, and a transition from one qualitative state to another.

The organization of the system is a complex and diverse process characterized by certain characteristics. In the formation of any system, firstly, communication between elements undergoes changes. Each element is functionally enriched. Secondly, the structural transformation of parts of the system, the limitation of some relationships and the expansion of others are assumed.

To bring elements into the system according to a given purpose, it is necessary to find a certain set of elements, reveal their functional properties, determine rational forms and methods for combining them. The unification is to create something qualitatively new, something that was not and could not be without this unification. To do this, you select characteristics or bases first to divide the elements, and then to join them into the system according to the law of proportionality. The law of proportionality defines the relationship between the organization of the system and the fact that there are certain quantitative and qualitative relations between each of the types of elements included in it, the elements themselves and between the characteristics of the elements. The law of proportionality determines the proportionality of parts combined as a whole, in which the effect of synergy is achieved.

To solve complex problems, a set of synergistic agents is offered. The ensemble constructed from there demonstrates the functions of an intellectual resonator assembled from components such as induction and deduction agents, synthesis, etc. Acting together as a single ensemble, intelligent agents are a powerful force with a high degree of intelligence, and solve many important life tasks in conditions of constantly changing conditions in the environment.

To develop the intelligence of the ensemble, you can create models of increasingly complex team interactions, including new classes of agents and protocols of their negotiations to achieve concessions, training from experience, etc. The higher the intelligence of each agent and the richer the possibilities of such communication between agents, the more complex and creative behavior the ensemble can demonstrate [3-6].

The synergistic principle directs to a new emerging:

1. analyze the change in the nature of the system interaction with the external environment;

2. Study the dynamics of the processes of system changes under the influence of the internal environment;

3. Study structures in an active state, capable of selfaction, spontaneous generation of new structures, selfmovement of the system; 
4. take into account the life cycle phase of the system development.

The synergistic principle is based on the fact that information is the main driving factor in self-organizing systems of any nature. It determines the direction and main phases of the development of evolutionary processes, the structure and stability of the existence of natural, social, or man-made systems that arise.

Translating the content of bright events can produce a resonant process and their reactions and stimulate a mass response. In such conditions, order parameters are duplicated, structures close to them are excited, and as a result, simple systems are combined into complex structures. Structures fall into the same pace, begin to develop at equal speed. Involving structures in an agreed pace and rhythm encourages interaction according to general rules.

The synergistic principle provides a single basis for selforganization. The law of self-organization: the ability of the system to adapt to external disturbances, changing, if necessary, its structure and maintaining integrity. The selforganization of the technological ensemble is carried out by a set of intelligent adaptive agents that provide a given operability regardless of the operating conditions [7]. The reasons for self-organization can be both external and internal.

Ensembles of agents with artificial intelligence on the synergistic principle of agent interaction implement selforganization. The intelligence of the ensemble manifests itself as an emerging property of a self-organizing system. There is a chain of agreed changes in the system of decisions by agents and spreads in the ensemble as a wave of approvals that determine the work of agents with artificial intelligence. Local interactions of agents form global structures, which in turn affect the behavior of the local agents that formed them and the intelligence of the ensemble.

\subsection{Means of Implementing Self-organizing Ensembles of Intelligent Agents with Collective Synergistic Interaction}

To create intelligent agents, use the following description and implementation languages:

1. agent implementation languages and software;

2. agent communication languages;

3. languages describing the behavior of agents and the laws of the environment;

4. presentation and knowledge management languages;

5. formalization languages and specifications of agents and multi-agent systems.

There are two approaches to designing agent interaction languages:

1. procedural - includes the exchange of procedural directives/commands.

2. declarative, where the relationship is based on declarative instructions, type of definitions, assumptions, knowledge, etc.

Agent interaction tools include agent communication languages: FIPA ACL, KQML. The agent communication language enables the exchange of knowledge and information between agents. The FIPA ACL manages judgments, rules, and actions.

In the context of the practical construction of agents and ensembles, the main role is played by agent programming and communication tools. Communication languages (ACL, KQML) and agent coordination (AgenTalk) ensure consistent interaction between agents, circulation of information, transfer of service requests, implement negotiation mechanisms, support cooperation between agents aimed at achieving a common goal and, as a result, the formation of agent teams. These languages can be considered as multilevel structures, including the level of knowledge presentation, the level of negotiation or coordination, the level of communication strategies, etc.

For agent programming, the following can be used: universal languages (Java, C, Visual Basic, etc.), Knowledge Presentation Languages (SL, KIF), Negotiation and Knowledge Sharing Languages (KQML, AgentSpeak, April), script languages (Tcl/Tk, Python, Perl 5, etc.), specialized languages (TeleScript, COOL, Agent0, AgentK, etc.), symbolic languages and logical programming languages $(\mathrm{Oz}$, ConGolog, IMPACT, Dylog, Concurrent METATEM, Ehhf, etc.), as well as other languages and agent development tools.

One of the most well-known and well-established integrated development environments for intelligent software agents is the AgentBuilder of Reticular Systems, Inc. This tool consists of two main components, Toolkit and the execution system. The toolkit includes:

1. agent-based software development process management tools;

2. means of analyzing the area of operation of the agent;

3. tools for designing and developing networks from interacting agents;

4. tools for modeling the behavior of individual agents;

5. tools for debugging and testing software agents.

AgentBuilder contains the Ummon tool for creating a selflearning agent. It also contains artificial intelligence methods for achieving human communication. The AgentBuilder Workbench provides developers with development tools and agent execution environments in the form of applications that display subject areas of tasks. The agent application runtime contains an agent execution processor. The processor uses efficient inference procedures by comparing agent behavior rules with agent beliefs determined by the current mental model and incoming messages. Based on the discussion, the processor performs certain actions related to the authority of the agent. The AgentBuilder toolkit is a modern and powerful tool for designing and implementing ensembles of intelligent agents.

JACK TM Intelligent Agents (JACK) is an agent-oriented development environment. The JACK Agent Programming Language offers the following features:

1. agent in JACK simulates intelligent entities;

2. ability, which collects into a whole functional components (events, plans, many beliefs and other abilities), for use by their agents; 
3. an event to simulate situations and messages to which the agent must be able to respond;

4. a plan that is designed to simulate a procedural description of how the agent manages this event (all actions taken by the agent are provided in advance and described in its plans);

5. many beliefs, for modeling the knowledge of the agent in the form of beliefs that adhere to the semantics of the closed or open world. This construction represents the agent's beliefs in the form of first-order relational tuples and ensures their logical consistency.

Agents work in such a way that agents process many plans and have access to descriptions of beliefs. Agents execute plans in event management tasks when they occur, comparing their beliefs when needed. These plans can initiate subtasks, which in turn can initiate their subtasks if the agent requires a time-consuming and complex response.

You have entered a new data structure named logical member, the value of which depends on the result of the request for multiple agent beliefs.

Ability to query multiple agents beliefs, using logical elements, by combining them to obtain the desired result. If the query succeeds, the logical element contains the desired value.

Agents created in JACK have the architecture inherent in intelligent agents. Thus, it is possible to model intelligent behavior in accordance with a theoretical model of agent architecture based on beliefs, desires and intentions. JACK intelligent agents are stand-alone software components that can exhibit intelligent behavior based on proactivity (targeting) and reactivity (event directed) on input signals. Each such agent has:

1. beliefs (this is his set of data on the world);

2. desires (a set of events to which it will respond and a set of goals to which it may wish);

3. intentions (a set of plans that describe how it can manage emerging goals and plans). A plan set describes the steps an agent must take when a specific event occurs or wants to achieve a specific result.

With agents, you can realize the following properties associated with intelligent behavior:

1. sustainable targeting - agents focus on targets rather than on selected methods to achieve them;

2. real-time context dependency - agents will monitor options that are applicable at each point in time and decide on follow-up actions based on conditions;

3. asserting the real-time approach - the agent will ensure that it follows the chosen course of action as long as certain conditions continue to be true;

4. concurrency - the ensemble of intellectual agents is multithreaded. If new goals and events occur, the agent is able to prioritize the demand for multitasking.

The self-organization of the interaction of intellectual agents is carried out according to criteria, rules and laws in a certain environment. Synergy between intelligent agents is achieved by setting up their self-organization to produce a result.

\section{The Embodiment of Virtual Creativity in a Technocratic Society}

The implementation of virtual creativity into the real life of technocratic society is carried out by cognitive robots and digital doubles through self-organizing ensembles of intellectual agents with synergistic interaction and creative communicative artificial intelligence. Creative cognitive robots work in the social sphere and in industrial production.

\subsection{Creative Cognitive Robots in the Social Sphere}

Robots become independent objects of social environment [8-10]. Social cognitive smart robots are used as hotel administrators, guides, security guards and other social professionals. The Russian robot guide conducts excursions (Figure 3).

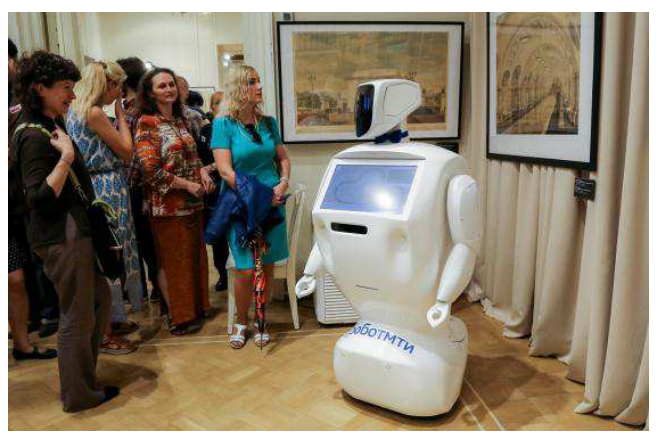

Figure 3. Russian robot guide.

The American ATLAS robot can work as a guard in an open area (Figure 4).

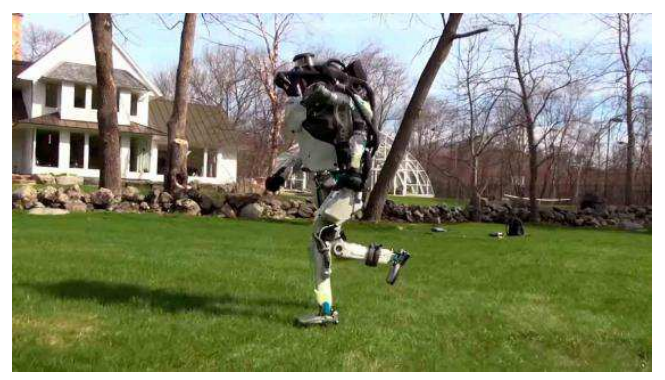

Figure 4. Mobile American robot security guard Atlas.

The Japanese robot administrator serves visitors to the hotel, in which most of the work is done by robots (Figure 5).

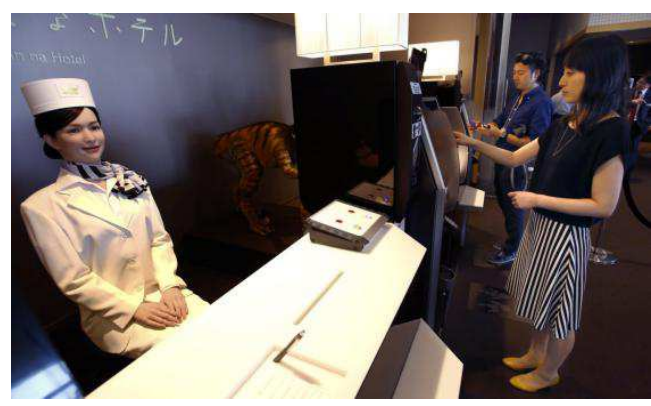

Figure 5. Japanese robot - hotel administrator, 


\subsection{Digital Doubles and Cognitive Robots in the Industry}

Digital double is a virtual prototype of a real object, group of objects, or processes. The digital double is used in conjunction with the physical object throughout the life cycle: at the stage of testing, refinement, operation and disposal.

Solutions using digital twins are built on a whole range of technologies. Numerical methods of modeling physical processes in object materials are used to build a complex model of a process twin. Using the Finite Element Analysis (FEA) method, you can model the behavior of complex systems by dividing them into many elements that are small enough to consider their properties as homogeneous. CAD models (computer-aided design/drafting, computer-aided design tools) are also used that carry information about the appearance and structure of objects, materials, processes, sizes, and other parameters. Digital doubles use companies of different industries [11-12].

Robotic perception is a process during which robots map the results of sensory measurements to internal structures for representing the medium. See industrial robotic complexes of different countries in Figures 6-7.

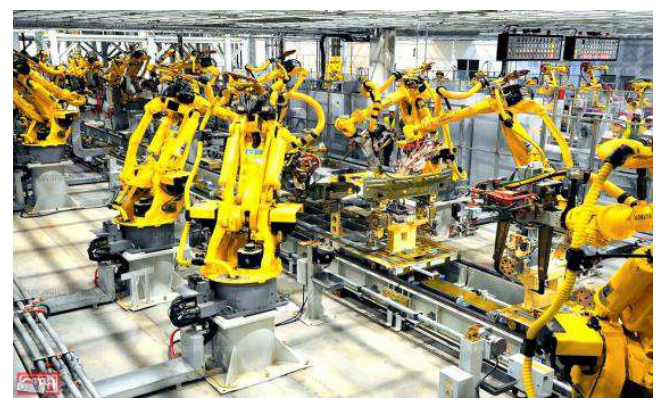

Figure 6. Chinese industrial robotic enterprise.

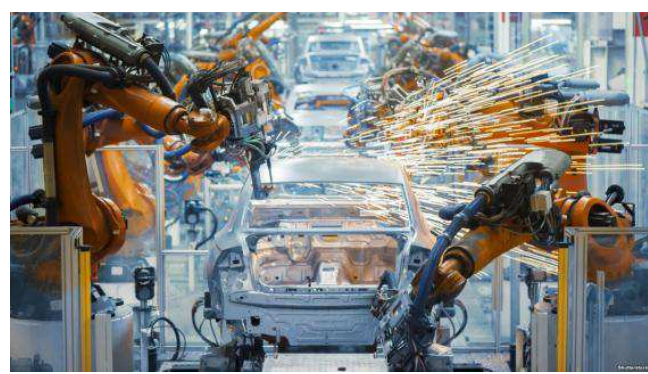

Figure 7. Korean industrial robotic automotive industry.

Based on smart big data accumulated during professional activities, the robot can realize new tasks. In the process of retraining new professional activities, an industrial cognitive robot accumulates a basic set of job implementations in the knowledge base. And also accumulates programs of functions of implementing professional actions in the base of skills. By means of more perfect sensors, sensors, controllers and other devices the cognitive robot expands behavioural skills. Based on the basic set of task implementations, the cognitive robot can implement combined tasks [13-16].

Cognitive robots and digital doubles through selfdeveloping ensembles of intelligent agents with synergistic interaction and creative communication artificial intelligence can master various high-tech professions and competencies. Their use in the industry increases labor productivity and economic efficiency of production. Their application in the social sphere improves the quality of life of a person and society. The widespread use of systems with creative communication artificial intelligence requires the development of an ethical standard so that their use does not cause harm. The development, implementation and use of an ethical standard for the use of cognitive robots and digital twins with creative communication artificial intelligence will increase the safety of their use through ethical communications. New concept of ethical communication is being introduced. Ethical communications are language, behavioural and operational relationships. Subjects of ethical communications are intellectual systems with linguistic, behavioral and active relationships. The objects of ethical communications are people. Ethical relationships between people and intellectual systems will be governed by an ethical standard.

\subsection{Standard case - «Ethical application of ensemble intelligent agents»}

Ensembles of agents with artificial intelligence are multiagent synergistic self-organizing systems that function according to the laws of development, synergy and selforganization. Intelligent agents use physical, informal and logical model of the environment. That is, they use both attributes and sets of entities, processes, relationships, etc.

Standard case Application of ensemble of intelligent interoperable agents defines parameters, characteristics, methods, human digital double models, knowledge, skills, behavior, images and other entities of intelligent virtual agent interaction (Table 1 - Table 7). Intelligent virtual agent interaction uses categorical method of utility and preference [2].

The synergistic mechanisms of self-organization of technological ensembles of intelligent agents are basic for standardization in the application of ensembles in various fields.Communicative-associative smart artificial intelligence with the help of an ensemble of diversified agents with a smart interface help control ethical application of ensemble intelligent agents [2].

The standard case «Ethical application of ensemble intelligent agents» contains seven tables.

Table 1. General.

\begin{tabular}{ll}
\hline Use case name & Ethical application of ensemble of intelligent agents \\
Application domain & Hi-Tech Labor Market \\
Deployment model & Human digital double \\
Status & Results of research: Creative Communication Artificial Intelligence \\
\hline
\end{tabular}




\begin{tabular}{|c|c|c|c|c|}
\hline Scope & \multirow{2}{*}{\multicolumn{4}{|c|}{ Industrial sectors and social services }} \\
\hline Objective(s) & & & & \\
\hline & $\begin{array}{l}\text { Short description (not } \\
\text { more than } 150 \text { words) }\end{array}$ & \multicolumn{3}{|c|}{$\begin{array}{l}\text { Ensemble is complex of intelligent agents with language, behavioral and active communications, } \\
\text { interacting through smart interface, implementing technological process, social services, multi-inter- } \\
\text { trans-disciplinary research, or production cycle. }\end{array}$} \\
\hline Narrative & $\begin{array}{l}\text { Complete } \\
\text { description }\end{array}$ & \multicolumn{3}{|c|}{$\begin{array}{l}\text { Ensemble is complex of intelligent agents with language, behavioral and active communications, } \\
\text { interacting through smart interface, implementing technological process, social services, multi-inter- } \\
\text { trans-disciplinary research, or production cycle. In the creative ensemble, the whole range of tasks by } \\
\text { certain rules is distributed among all agents. Job allocation means assigning each agent a role whose } \\
\text { complexity is determined by the agent's capabilities. To organize the task distribution process, the } \\
\text { creative ensemble creates either a distributed problem solution system or decentralized artificial } \\
\text { intelligence. In the first version, the process of decomposition of the global problem and the inverse } \\
\text { process of composition of the found solutions takes place under the control of some single "center." At } \\
\text { the same time, the creative ensemble is designed strictly from top to bottom, based on the roles defined } \\
\text { for the agents and the results of dividing the global task into subtasks. In the case of decentralized } \\
\text { artificial intelligence, task distribution occurs during agent interaction and is synergistic. }\end{array}$} \\
\hline Stakeholders & \multicolumn{4}{|c|}{ Highly technological producer and user } \\
\hline $\begin{array}{l}\text { Stakeholders' } \\
\text { assets, values }\end{array}$ & \multicolumn{4}{|c|}{ Reputation, responsibility, security } \\
\hline $\begin{array}{l}\text { System's threats and } \\
\text { vulnerabilities }\end{array}$ & \multicolumn{4}{|c|}{ Legal and ethical aspects of interaction with society } \\
\hline \multirow{6}{*}{$\begin{array}{l}\text { Key performance } \\
\text { indicators (KPIs) }\end{array}$} & ID & Name & Description & $\begin{array}{l}\text { Reference to } \\
\text { mentioned use } \\
\text { case objectives }\end{array}$ \\
\hline & 1 & $\begin{array}{l}\text { AI management of } \\
\text { professional } \\
\text { cooperation } \\
\text { process }\end{array}$ & $\begin{array}{l}\text { Creative process management technology can itself predict the } \\
\text { optimal timing of individual stages based on accumulated } \\
\text { information about their labor intensity, choice of equipment } \\
\text { loading route and competencies of intelligent agents. } \\
\text { Streamline processes and automatically delegate tasks. }\end{array}$ & $\begin{array}{l}\text { Improve of } \\
\text { synergy } \\
\text { between agents }\end{array}$ \\
\hline & 2 & $\begin{array}{l}\text { Productivity and } \\
\text { quality AI }\end{array}$ & $\begin{array}{l}\text { Creative communication artificial intelligence works with } \\
\text { fewer errors and is safer. Creative communication artificial } \\
\text { intelligence improves the quality of life of a person and } \\
\text { society in everyday concerns, as well as productivity in high- } \\
\text { tech industry and production. }\end{array}$ & $\begin{array}{l}\text { Improve of } \\
\text { efficiency }\end{array}$ \\
\hline & Task(s) & \multicolumn{3}{|c|}{ 1. Safe interaction of technocratic societies. } \\
\hline & Method(s) & \\
\hline & Hardware & & & Supercomputer with Strong Artificial Distributed Intelligence \\
\hline \multirow{2}{*}{ AI features } & Topology & \multicolumn{3}{|c|}{ Distributed Modular Interconnect Topology } \\
\hline & $\begin{array}{l}\text { Terms and concepts } \\
\text { used }\end{array}$ & \multicolumn{3}{|c|}{$\begin{array}{l}\text { Technocratic societies, synergy of interaction intelligent agents, ethical language behavioural and active } \\
\text { communication, legal regulation, utility and preference criteria, creative communication safe artificial } \\
\text { intelligence. }\end{array}$} \\
\hline $\begin{array}{l}\text { Standardization } \\
\text { opportunities/ } \\
\text { requirements }\end{array}$ & \multicolumn{4}{|c|}{ Creative communication artificial intelligence requires process standardization, as does every human activity. } \\
\hline Challenges and & \multicolumn{4}{|c|}{ Qualitatively new type of thinking not available to humans. } \\
\hline & Description & \multirow{2}{*}{\multicolumn{3}{|c|}{$\begin{array}{l}\text { Security and ethical and legal aspects } \\
\text { A universal approach to the ethical and safe use of intellectual agent ensembles with language behavioral } \\
\text { and active communications. }\end{array}$}} \\
\hline Societal concerns & SDGs to be achieved & & & \\
\hline
\end{tabular}

Table 2. Data.

\begin{tabular}{ll}
\hline Data characteristics & \\
Description & Creative Communication Artificial Intelligence Professional Images \\
Source & Criteria and Technology of Creative Communication Artificial Intelligence \\
Type & Smart \\
Volume (size) & Hi-Tech Labor Market \\
Velocity (e.g. real time) & Supercomputering velocity \\
Variety (multiple datasets) & Streams of Professional Images \\
Variability (rate of change) & Retraining \\
Quality & High \\
\hline
\end{tabular}


Table 3. Process scenario.

\begin{tabular}{|c|c|c|c|c|c|}
\hline \multicolumn{6}{|c|}{ Scenario conditions } \\
\hline $\mathbf{N}$. & Scenario name & Scenario description & Triggering event & Pre-condition & Post-condition \\
\hline 1 & Training & $\begin{array}{l}\text { Training of intellectual agents in } \\
\text { professional images and } \\
\text { language, behavioral and active } \\
\text { communications. }\end{array}$ & $\begin{array}{l}\text { By technological process of } \\
\text { modeling flow of professional } \\
\text { images and language, behavioral } \\
\text { and active communications }\end{array}$ & $\begin{array}{l}\text { Formatting of professional } \\
\text { images and language, } \\
\text { behavioral and active } \\
\text { communications }\end{array}$ & $\begin{array}{l}\text { Management of } \\
\text { safety }\end{array}$ \\
\hline 2 & Evaluation & Trained model & $\begin{array}{l}\text { Development of technological } \\
\text { thinking and behaviour }\end{array}$ & $\begin{array}{l}\text { Cognitive thinking patterns } \\
\text { and psychological } \\
\text { behaviors }\end{array}$ & $\begin{array}{l}\text { Meeting KPI } \\
\text { requirements is } \\
\text { condition of synergy }\end{array}$ \\
\hline 3 & Execution & Model and Technology Tooling & Interaction & Activization of Model & $\begin{array}{l}\text { Completion of } \\
\text { interaction }\end{array}$ \\
\hline 4 & Retraining & $\begin{array}{l}\text { Retrain model with training } \\
\text { professional images and } \\
\text { language, behavioral and active } \\
\text { communications. }\end{array}$ & $\begin{array}{l}\text { New professional activities and } \\
\text { competencies }\end{array}$ & $\begin{array}{l}\text { Additional images and } \\
\text { communications }\end{array}$ & $\begin{array}{l}\text { Combining images } \\
\text { and communications }\end{array}$ \\
\hline
\end{tabular}

Table 4. Training.

\begin{tabular}{|c|c|c|c|c|c|}
\hline Scenario name & Training & & & & \\
\hline Step No. & Event & $\begin{array}{l}\text { Name of } \\
\text { process/Activity }\end{array}$ & Primary actor & $\begin{array}{l}\text { Description of } \\
\text { process/activity }\end{array}$ & Requirement \\
\hline 1 & $\begin{array}{l}\text { Sample professional } \\
\text { images and language, } \\
\text { behavioral and active } \\
\text { communications is ready }\end{array}$ & $\begin{array}{l}\text { Specification and } \\
\text { classification }\end{array}$ & Manufacturer & $\begin{array}{l}\text { Transform sample } \\
\text { professional images and } \\
\text { language, behavioral and } \\
\text { active communications }\end{array}$ & $\begin{array}{l}\text { Creative Communication } \\
\text { Artificial Intelligence } \\
\text { Software }\end{array}$ \\
\hline 2 & Completion of Step 1 & $\begin{array}{l}\text { Creating Experimental } \\
\text { professional images and } \\
\text { language, behavioral and } \\
\text { active communications }\end{array}$ & Manufacturer & $\begin{array}{l}\text { Development of language, } \\
\text { behavioral and active } \\
\text { communications through job } \\
\text { modelling }\end{array}$ & Software of modelling \\
\hline 3 & Completion of Step 2 & Model training & $\begin{array}{l}\text { AI solution } \\
\text { provider }\end{array}$ & $\begin{array}{l}\text { Model professional images } \\
\text { and language, behavioral and } \\
\text { active communications } \\
\text { created by Step } 2\end{array}$ & $\begin{array}{l}\text { Sample professional } \\
\text { images and language, } \\
\text { behavioral and active } \\
\text { communications }\end{array}$ \\
\hline
\end{tabular}

Table 5. Evaluation

\begin{tabular}{|c|c|c|c|c|c|}
\hline Scenario name & Evaluation & & & & \\
\hline Step No. & Event & $\begin{array}{l}\text { Name of } \\
\text { process/Activity }\end{array}$ & Primary actor & Description of process/activity & Requirement \\
\hline 1 & $\begin{array}{l}\text { Completion of } \\
\text { training/retraining }\end{array}$ & Research & Manufacturer & $\begin{array}{l}\text { Model of sample experimental data set } \\
\text { created }\end{array}$ & $\begin{array}{l}\text { Ethical language, } \\
\text { behavioral and active } \\
\text { communications }\end{array}$ \\
\hline 2 & $\begin{array}{l}\text { Completion of } \\
\text { Step } 1\end{array}$ & Identification & $\begin{array}{l}\text { AI solution } \\
\text { provider }\end{array}$ & $\begin{array}{l}\text { Based on new data, confirm that the } \\
\text { ensemble of intelligent agents performs } \\
\text { trained professional process. }\end{array}$ & Synergy \\
\hline 3 & $\begin{array}{l}\text { Completion of } \\
\text { Step } 2\end{array}$ & Evaluation & Manufacturer & Comparison of Step 1 and Step 2 & Synergy \\
\hline \multicolumn{2}{|c|}{ Input of evaluation } & \multicolumn{4}{|c|}{ Ethical language, behavioral and active communications } \\
\hline
\end{tabular}

Table 6. Execution.

\begin{tabular}{llllll}
\hline Scenario name & Execution & & & & \\
\hline Step No. & Event & $\begin{array}{l}\text { Name of } \\
\text { process/Activity }\end{array}$ & Primary actor & Description of process/activity & Requirement \\
\hline 1 & $\begin{array}{l}\text { Analysis of } \\
\text { modeling results }\end{array}$ & Research & Manufacturer & $\begin{array}{l}\text { Development of set of experimental data } \\
\text { through job modelling }\end{array}$ & Compatibility \\
& $\begin{array}{l}\text { Completion of Step } \\
1 \text { and Step 2 }\end{array}$ & Identification & AI solution provider & $\begin{array}{l}\text { Based the modification of } \\
\text { communications of professional images } \\
\text { according to the created experimental set. }\end{array}$ & Synergy \\
Input of Execution & Modification of communications of professional images & \\
Output of Execution & Synergy, compliance with ethical conditions of application and no signs of harm or damage \\
\hline
\end{tabular}


Table 7. Retraining.

\begin{tabular}{|c|c|c|c|c|c|}
\hline Scenario name & Retraining & & & & \\
\hline Step No. & Event & $\begin{array}{l}\text { Name of process / } \\
\text { Activity }\end{array}$ & Primary actor & Description of process/activity & Requirement \\
\hline 1 & $\begin{array}{l}\text { New professional activities } \\
\text { and competencies }\end{array}$ & Research & Manufacturer & $\begin{array}{l}\text { Additional professional images } \\
\text { and language, behavioral and } \\
\text { active communications }\end{array}$ & Completeness \\
\hline 2 & Completion of Step 1 & $\begin{array}{l}\text { Experimental data } \\
\text { set creation }\end{array}$ & Manufacturer & $\begin{array}{l}\text { Combining professional images } \\
\text { and language, behavioral and } \\
\text { active communications }\end{array}$ & Compatibility \\
\hline & Completion of Step 2 & Model training & AI solution provider & Comparison of phase 2 results & Synergy and quality \\
\hline \multicolumn{2}{|c|}{ Specification of retraining data } & \multicolumn{4}{|c|}{ Data of new professional activities and competencies } \\
\hline
\end{tabular}

\section{Conclusion}

In the era of technological development, creative communication safe artificial intelligence is in demand in various areas of social life and industrial production. Ensembles of intellectual agents allow you to create professional images with language, behavioral and active communications, when each image is implemented by an agent with creative communication safe artificial intelligence. Language, behavioral and active communications of intellectual agents implement collective activities. The ethical standard through intelligent agents allows you to regulate the safe use of ensembles made of robots and digital doubles with creative communication artificial intelligence in the social sphere, industry and other professional fields. The use of systems with creative communication safe artificial intelligence requires responsibility from the developer and owner for harming others. If harm to others occurred due to the mistakes of the developer, then he bears responsibility and costs. If the damage to others occurred due to the fault of the owner due to non-compliance with the terms of use, then he bears responsibility and costs. Ethical standard and legal regulation will help to become active members of society systems with creative communication artificial intelligence. Ensembles of intellectual agents with creative communication ethical artificial intelligence will be able to safely work with society as professional images with skills, knowledge and competencies, implemented in the form of retrained digital twins and cognitive robots that interact through language, behavioral and active ethical communications.

\section{References}

[1] Evgeniy Bryndin. Practical Development of Creative LifeSaving Strong Artificial Intelligence. Communications, Volume.7, Issue 2, 2019. Pages: 31-39.

[2] Evgeniy Bryndin. Communicative-associative development of smart artificial intelligence by criteria with the help of ensembles of diversified agents. International Journal of Intelligent Information Systems. Volume 9, Issue 4, 2020. pp. 24-34.

[3] Evgeniy Bryndin. Collaboration of Intelligent Interoperable Agents via Smart Interface. International Journal on Data Science and Technology, Vol. 5, № 4. 2019. Pages: 66-72.

[4] Evgeniy Bryndin. Development of Artificial Intelligence by Ensembles of Virtual Agents on Technological Platforms. COJ
Technical \& Scientific Research.2(4). 2020. Pages: 1-8.

[5] Masloboev A.V., Langhans M. A multi-agent system for management information support of regional innovations. Scientific and Technical Journal of Information Technologies, Mechanics and Optics, 2018, vol. 18, no. 4, pp. 630-638.

[6] Oleg Vasylovych Moroz. Model of Self-organizing Knowledge Representation and Organizational Knowledge Transformation, American Journal of Artificial Intelligence. Vol. 4, No. 1, 2020, pp. 1-19. doi: 10.11648/j.ajai.20200401.11.

[7] Evgeniy Bryndin. Technology Self-organizing Ensembles of Intelligent Agents with Collective Synergetic Interaction. Automation, Control and Intelligent Systems. Vol. 8, Issue 4, 2020, pp. 29-37.

[8] Wu Jun. Research on the Framework of Smart City Operating System Based on New ICTs. American Journal of Artificial Intelligence. Volume 4, Issue 1, June 2020, Pages: 36-41.

[9] Evgeniy Bryndin. Cognitive Robots with Imitative Thinking for Digital Libraries, Banks, Universities and Smart Factories. International Journal of Management and Fuzzy Systems. V.3, N.5, 2017, pp 57- 66.

[10] CRONEMBERGER F, GIL-GARCIA J R. Big data and analytics as strategies to generate public value in smart cities: proposing an integrative framework. Switzerland: Springer Nature, 2019.

[11] Stewart Russell, Peter Norvig. Artificial Intelligence: Modern Approach. Williams, 2019. 1408 p. ISBN: 978-5-8459-1968-7.

[12] Evgeniy Bryndin. Mainstreaming technological development of industrial production based on artificial intelligence. COJ Technical \& Scientific Research, 2(3). 2019. Pages: 1-5.

[13] Evgeniy Bryndin. Robots with Artificial Intelligence and Spectroscopic Sight in Hi-Tech Labor Market. International Journal of Systems Science and Applied Mathematic, V. 4, № 3, 2019. Pages: 31-37.

[14] Evgeniy Bryndin. Increase of Safety Use Robots in Industry 4.0 by Developing Sensitivity and Professional Behavioral Skills. American Journal of Mechanical and Industrial Engineering. Volume 5, Issue 1, 2020. Pages: 6-14.

[15] Fatima Kalna. A Meta-model for Diverse Data Sources in Business Intelligence. American Journal of Embedded Systems and Applications, Volume 7, Issue 1, June 2019, Pages: 1-8.

[16] Evgeniy Bryndin. Formation and Management of Industry 5.0 by Systems with Artificial Intelligence and Technological Singularity. American Journal of Mechanical and Industrial Engineering. Volume 5, Issue 2. 2020. pp. 24-30. 